\title{
Now for Something Entirely Different
}

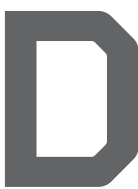

EPARTING FROM MY usual stream of consciousness, this column is about three books I have just read: Bullsh $^{*} t^{\mathrm{a}}$ Future Babble ${ }^{\mathrm{b}}$ and Deep Future. ${ }^{\mathrm{c}}$ The first two get at the proliferation of wrong but persuasive assertions about the past, present, or future. The last one appeals to logic and humility. I draw them to your attention because I found them usefully thought-provoking and often very clarifying.

In Bullsh*t, John Grant systematically demolishes a wide range of mistaken beliefs and illustrates human foibles that often lead us to believe the unbelievable because we want to, not because the arguments for somehow outweigh the arguments against. In a world filled with misinformation (whether intentional or out of ignorance), disinformation, and scientific theories that have been falsified by new experimental evidence, we need all the tools we can muster to put claims to rigorous test. This takes real work and even some pain as some favorite notion is undermined by counterevidence. Good science demands that we be prepared to abandon long-held beliefs when confronted by new facts. Once it was thought that neutrinos had no mass, now we find they have very small, variable mass and the various flavors of neutrinos oscillate from one flavor to another while traveling from their origins. Current evidence makes extremely lightweight

a Bullsh ${ }^{*} t$, J. Grant (pseudonym of Paul Barnett), MJF Books, NY, 2014.

b Future Babble, D. Gardner, Penguin Group, NY, 2011.

c Deep Future: The Next 100,000 Years on Earth, C. Stager, St. Martin's Press, 2011. objects even weirder than they were when they were first predicted to account for conservation of mass/energy in subatomic interactions. While Grant does not deal with neutrinos, he does cope with endless examples of "junk science, bogus claims, wacky theories, and general human stupidity" to quote the subtitle of his book.

In Future Babble, Dan Gardner goes to great lengths to explain the dynamics and even fundamental aspects of human nature that lead us to accept predictions that prove to be wrong. He explains Paul Ehrlich's elevation and recognition (that is, many prizes and awards) for his Population Bomb ${ }^{\mathrm{d}}$ book and the subsequent failure of most of his predictions to materialize. Gardner presents examples of the rationalizations that lead people to cling to favored theories and beliefs. He distinguishes "hedgehogs" from "foxes" in that the hedgehog knows only one thing and is certain of it (and conveys this conviction emphatically) and the foxes know they don't know everything and are prepared to cope with discovering error and adapting to it. We learn what it is the hedgehogs project that induces some to believe them and not others who have humility in the face of unknown unknowns..$^{e}$ We crave certainty and predictability and uncertainty makes us uncomfortable. Even our brains try hard to find patterns in noise to make sense of the world around us.

Both of these books should be required reading for people struggling to

d The Population Bomb, P. Ehrlich, Buccaneer Books, NY, 1971.

e Whatever else you may think of Donald Rumsfeld, his explication of "unknown unknowns" is creditable. filter good information from bad in all sources, but especially in our increasingly online world.

In Deep Future, Curt Stager, a climatologist, lays out the consequences of global warming, citing credible reasons for human contribution to increased greenhouse gases that trap heat in the atmosphere. The author's most interesting observations takes us 55 million years into the past when the so-called PaleoceneEocene Thermal Maximum (PETM) ${ }^{\mathrm{f}}$ produced a warming period lasting about 200,000 years after which Earth was returned to its previously scheduled ice age. Stager uses a significant body of scientific evidence to show how increased atmospheric carbon content produced measurable and significant increases in average temperature and increased ocean acidity with consequences for flora and fauna. A surprise for me was his observation that the warming we have apparently launched may actually postpone the next ice age (predicted to come in about 50,000 years based on detectable cycles) for up to 400,000 years. He points out that ice ages may be far more damaging to human society than global warming despite the predicted and very negative side effects of the latter.

If you read any of these, let me know what you think.

f https://en.wikipedia.org/wiki/

Paleocene\%E2\%80\%93Eocene_Thermal_Maximum

Vinton G. Cerf is vice president and Chief Internet Evangelist at Google. He served as ACM president from 2012-2014.

Copyright held by author 